Original Research Paper

\title{
Effect of Varying Loads on Wear Behaviour of Constructional Steel
}

\author{
${ }^{1}$ Alo Francis Ireti, ${ }^{2}$ Emordi Ngozi, ${ }^{1}$ Kunle Michael Oluwasegun, \\ ${ }^{1}$ Dayo Adeyemi Isadare and ${ }^{3}$ Adedayo Adewale Oyedele \\ ${ }^{I}$ Department of Material Science and Engineering, Obafemi Awolowo University, Ile-Ife, Nigeria \\ ${ }^{2}$ Department of Metallurgical Engineering, Delta State Polytechnic, Ogwashi uku, Nigeria \\ ${ }^{3}$ Prototype Engineering Development Institute, Ilesa, Nigeria
}

\author{
Article history \\ Received: 05-01-2018 \\ Revised: $17-01-2018$ \\ Accepted: 03-02-2018 \\ Corresponding Author: \\ Alo Francis Ireti \\ Department of Material Science \\ and Engineering, Obafemi \\ Awolowo University, Ile-Ife, \\ Nigeria \\ Email: iretispecial2005@yahoo.com
}

\begin{abstract}
This study examined the effect of varying loads on wear behaviour of Ife constructional steel. The wear measurements were determined under normal ranging from 5 to $25 \mathrm{~N}$ at interval of $5 \mathrm{~N}$ incremental. The morphology of the corroded samples were carried out using optical microscopy and Scanning Electron Microscopy (SEM). When a load of $5 \mathrm{~N}$ was used, the wear was found to be mild with abrasion, adhesion and oxidation but at higher load of $15 \mathrm{~N}$, the wear was governed by delamination, oxidation and plastic deformation but with load $25 \mathrm{~N}$, we noticed a severe crack propagation on the surface of the material. As the load increases the wear track length decreases resulting in the widening of the ploughing breadth. The COF of $5 \mathrm{~N}$ load oscillates to 0.60 and slides down to 0.47 at 80 $\mathrm{sec}$ and then oscillate uniformly to $1000 \mathrm{sec}$, however at $25 \mathrm{~N}$, the waveform increases to 0.50 and slides down to 0.40 before oscillating to $1000 \mathrm{sec}$ from this waveform it was clearly seen that the time to reach steady friction varies for different loads., the time for higher load to reach steady friction is less. This is because the surface roughness and other parameters attain a steady level at a shorter period of time with increase in load.
\end{abstract}

Keywords: Ife Steel, The Wear Measurements, Optical Microscope and Scanning Electron Microscopy

\section{Introduction}

Steel exhibits desirable physical properties that makes it one of the most versatile structural material in use. Its great strength, uniformity, light weight, ease of use and many other desirable properties makes it the material of choice for numerous structures such as steel bridges, high rise buildings, towers and other structures (Assakkaf, 2002).

In addition, the mechanical properties of low carbon steel such as strength formability, ductility, fatigue strength and surface hardness, amongst others enhances its performance in service. Studies have also shown that failure of carbon steels can result from production methods, use of substandard material, poor design, manufacturing errors due to poor machining, or failure from a phenomenon called fatigue (Ajayi et al., 2013; Joseph et al., 2013; Joseph and Alo, 2014) on assessment of the microstructure and mechanical properties of $0.26 \%$ low carbon steel under different cooling media concluded that the performance of low carbon steel in service depends on intrinsic factors which include its grain size, presence of defects, its chemical composition, ultimate tensile strength, etc. as well as extrinsic factors. Moreover, properties like strength, ductility, fatigue and hardness have some direct impact on the mechanical properties of low carbon steel which may enhance its performance in service. Kumar and Pathak (2016) defined wear as removal of material from solid surfaces as a result of mechanical action. It is a characteristic feature of the wear process that the amount of material removed is quite small.

Almost all machines lose their durability and reliability due to wear and the possibilities of new advanced machines are reduced because of wear problems. Therefore, wear control has become a strong need for the advanced and reliable technology of the future (Kato, 2001), there are different types of wear. Wear is classified into two namely: Wear dominated by mechanical behaviour of materials (asperity deformation 
and removal, wear caused by ploughing, delamination wear, adhesive wear, abrasive wear, fretting wear and wear by solid particle impingement) and wear dominated by chemical behaviour of materials (solution wear, oxidation wear, diffusion wear, wear by melting of the surface layer and adhesive wear at high temperatures) (Burwell, 1957/58). It also comprises of two stages: Running-in and steady-state. The running-in stage is defined as the initial transient sliding process occurring in newly established contacts, often accompanied by transients in coefficient of friction, wear rate, or both, which may be uncharacteristic of the long-term behaviour of a given tribological system (Maich, 2016) there have been a lot of researches on wear and their effect on performance on steel (Gupta and Pandey, 2000; Tyagi et al., 2004; Mohan et al., 2002; Kaul et al., 2005).

Abrasive wear occurs when a hard rough surface slides across a softer surfaces. It is the loss of material due to hard particles or hard protuberances that are forced against and move along a solid surface (Gates, 1998) in this study wear properties of selected steel were investigated. The microstructures were analysed by Optical Microscope (OM) and Scanning Electron Microscopy (SEM), while CERT UMT -2 Tribology Machine was used for the wear testing.

\section{Experimental Procedures} follows.

The experimental procedures were carried out as

Table 1: Chemical composition of Ife steel (mass fraction, wt \%)

\begin{tabular}{|c|c|c|c|c|c|c|c|c|c|c|c|}
\hline Steel type & $\mathrm{C}$ & $\mathrm{Si}$ & $\mathrm{Mn}$ & $\mathrm{P}$ & $\mathrm{S}$ & $\mathrm{Cr}$ & $\mathrm{Ni}$ & Mo & $\mathrm{Cu}$ & $\mathrm{V}$ & $\mathrm{Fe}$ \\
\hline IFE steel & 0.320 & 0.203 & 0.514 & 0.003 & 0.038 & 0.215 & 0.093 & 0.0001 & 0.307 & 0.0001 & 98.255 \\
\hline
\end{tabular}

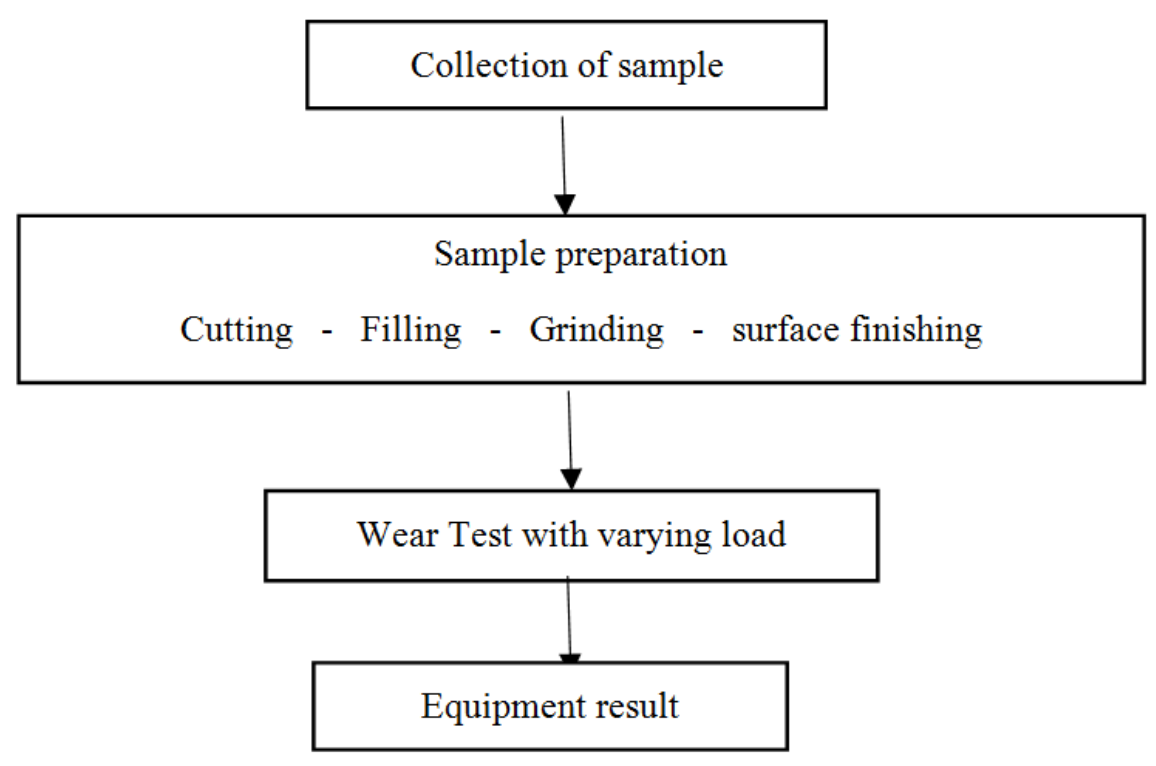

Fig. 1: Proposed flowchart for the experiment 


\section{Microstructural Evaluation}

The samples morphology were observed with an accuscope optical microscope equipped with a camera and a field emission scanning electron microscope (Jeol JSM-7600F) equipped with Energy Dispersive X-ray Spectrometer (EDS).

\section{Results and Discussion}

Figure 3 showed the optical microscope of Ife steel. The white phase is known as the ferrite while the black phase is known as the pearlite and the micrograph has more of the pearlite phases than the white phase.
Scanning electron micrographs of the worn surfaces are shown in Fig. 4 to 6, Indistinct grooves and fine scratches were formed on the worn surface. The wear mechanism are characterised by the formation of the grooves, which are produced by the ploughing action of hard asperities on the counter disc and hardened worn debris. As the load increases, a severe wear was observed followed by a distinct crack propagation as could be seen in Fig. 2. When a load of $5 \mathrm{~N}$ was used, the wear was found to be mild with abrasion, adhesion and oxidation but at higher load of $15 \mathrm{~N}$, the wear was governed by delamination, oxidation and plastic deformation in Fig. 3 and it is in agreement with the report of Elhadia et al. (2016).

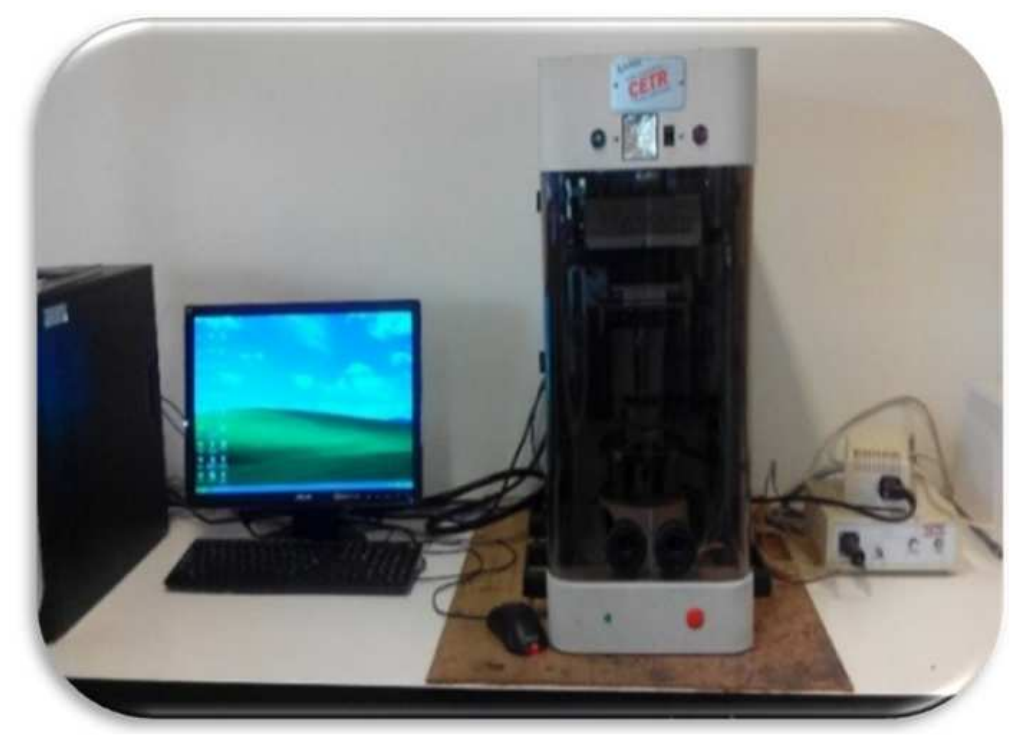

Fig. 2: Image of the CETR-UMT3 pin-on-disk testing apparatus

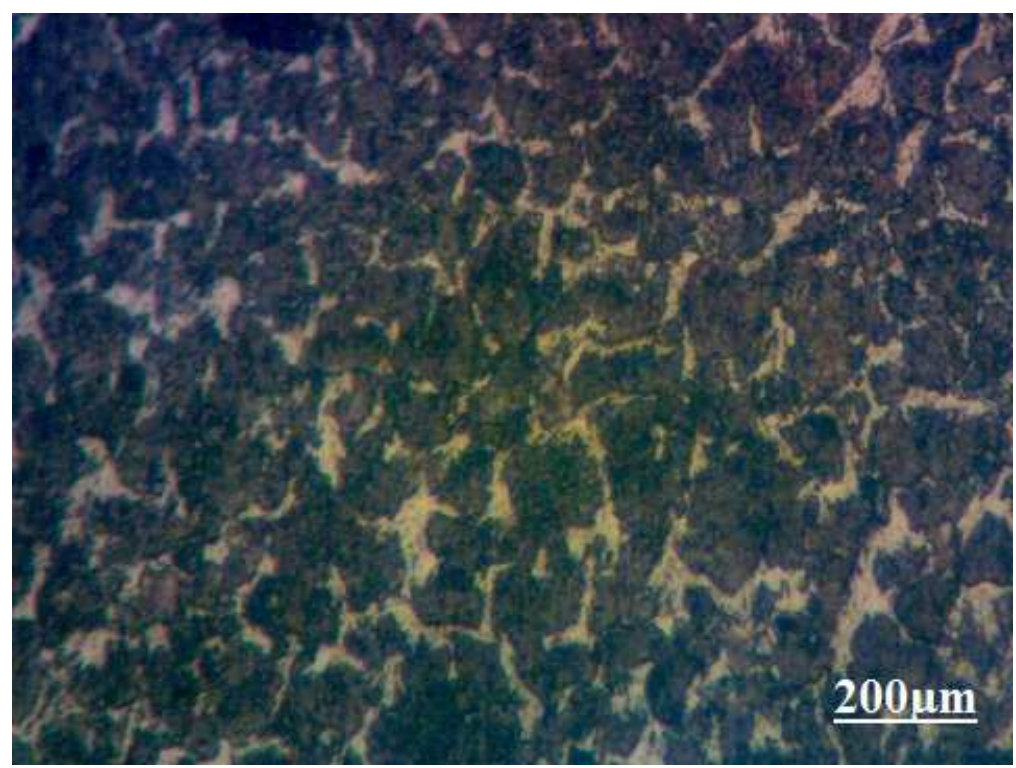

Fig. 3: Optical Microscope (OM) of Ife steel 


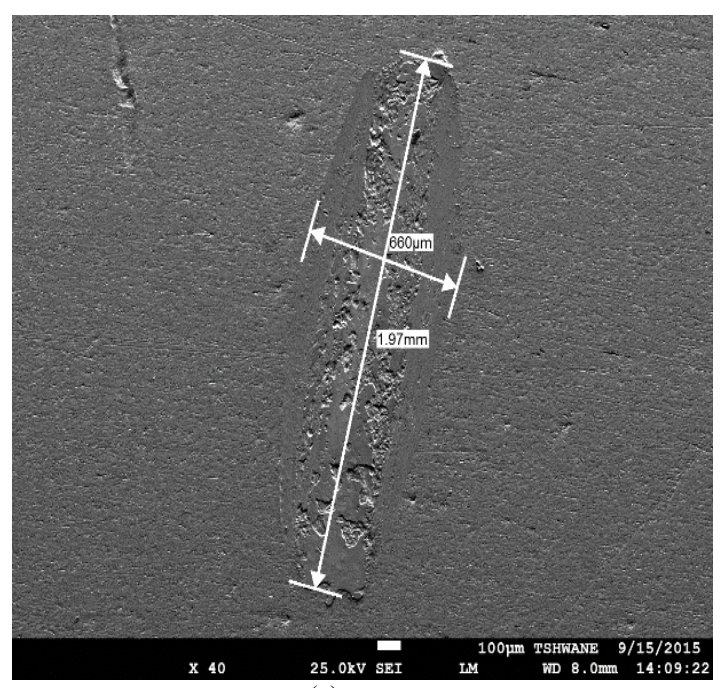

(a)

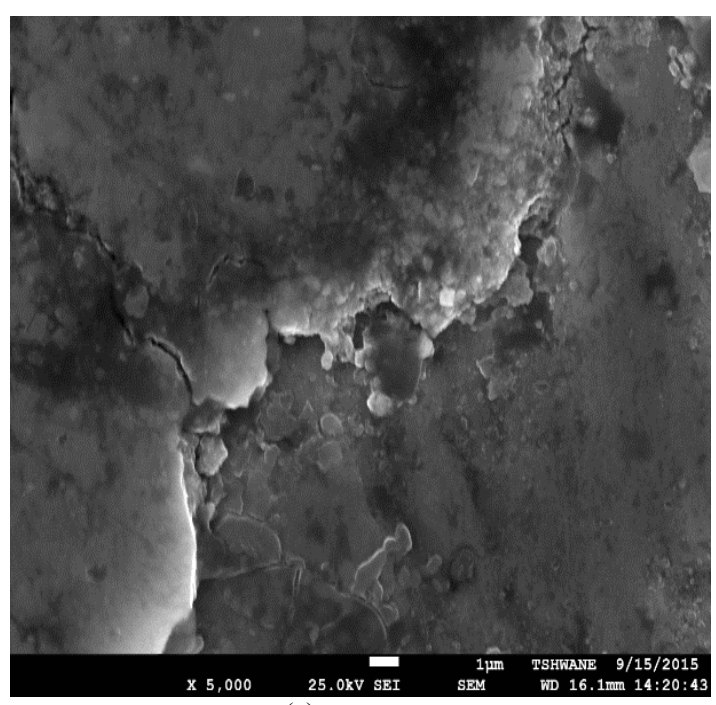

(c)

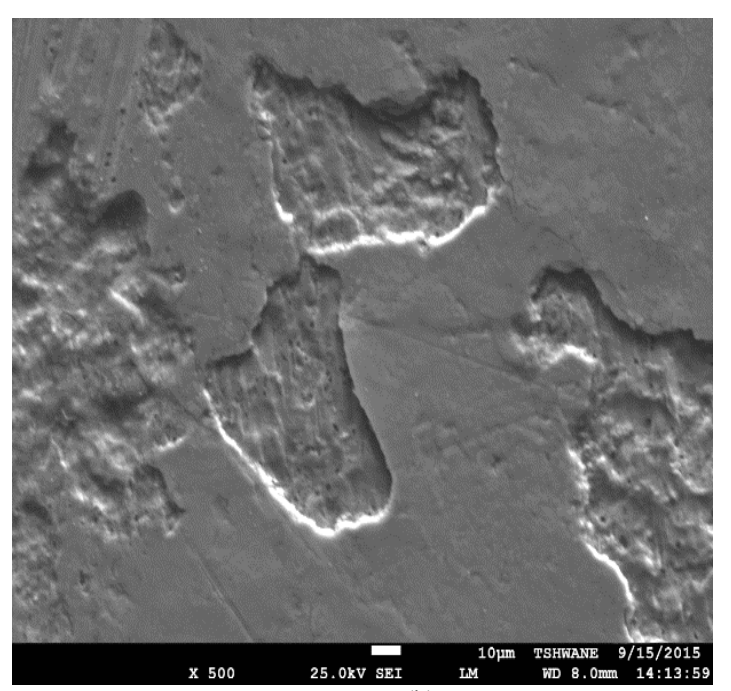

(b)

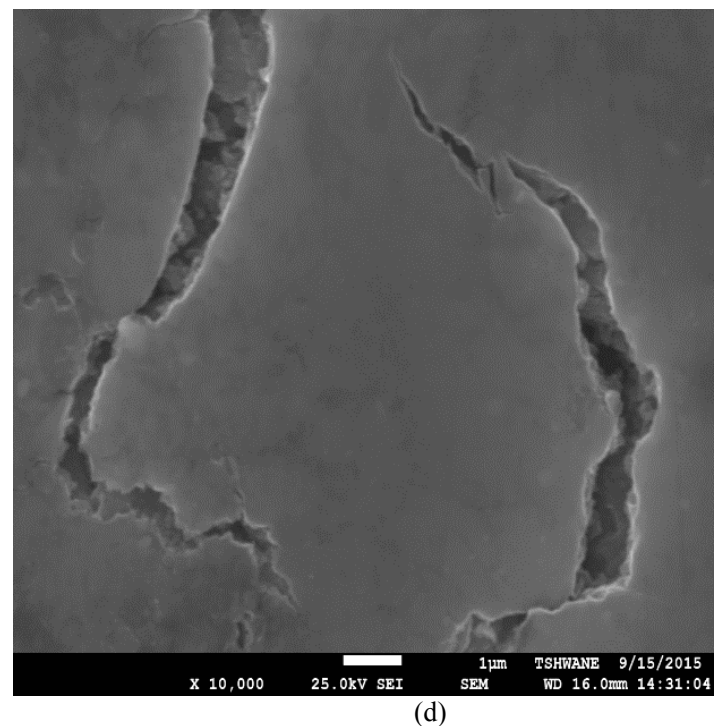

(d)

Fig. 4: SEM micrograph of Ife Steel with load $5 \mathrm{~N}$ showing the wear track and the different magnification

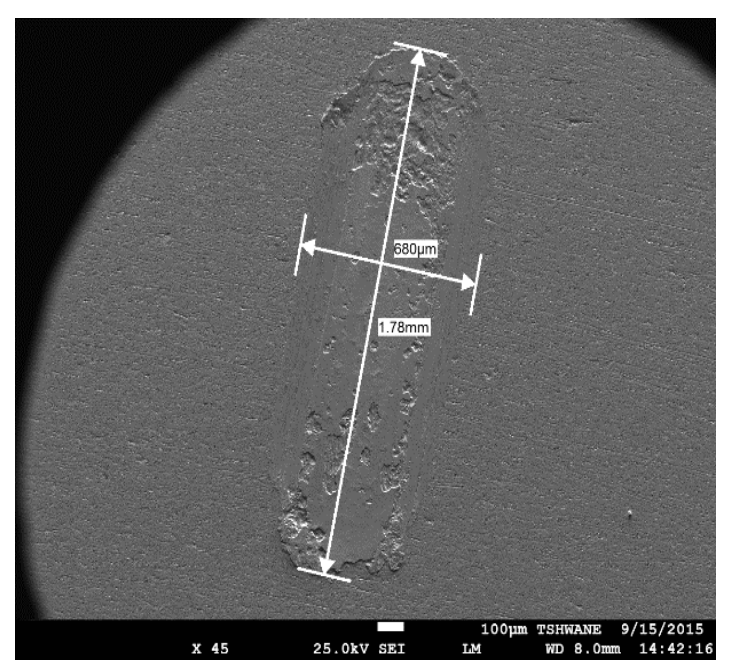

(a)

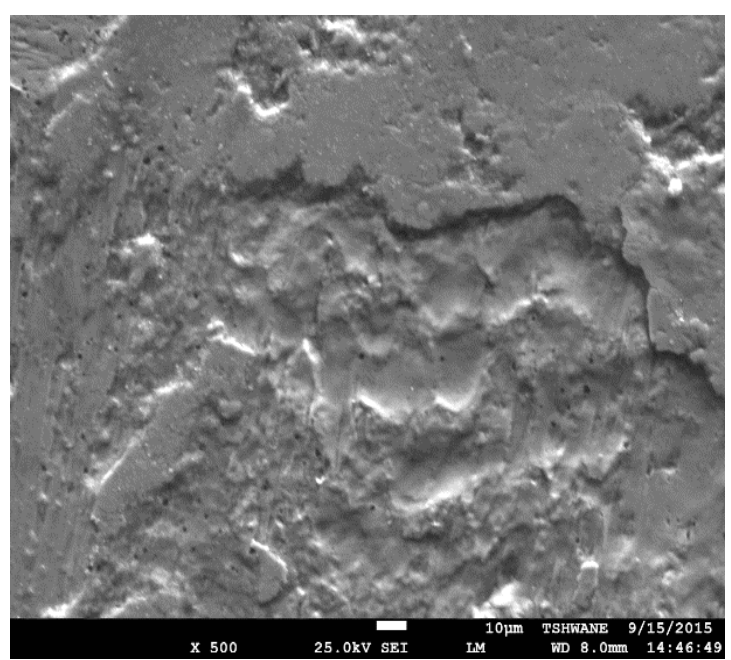

(b) 


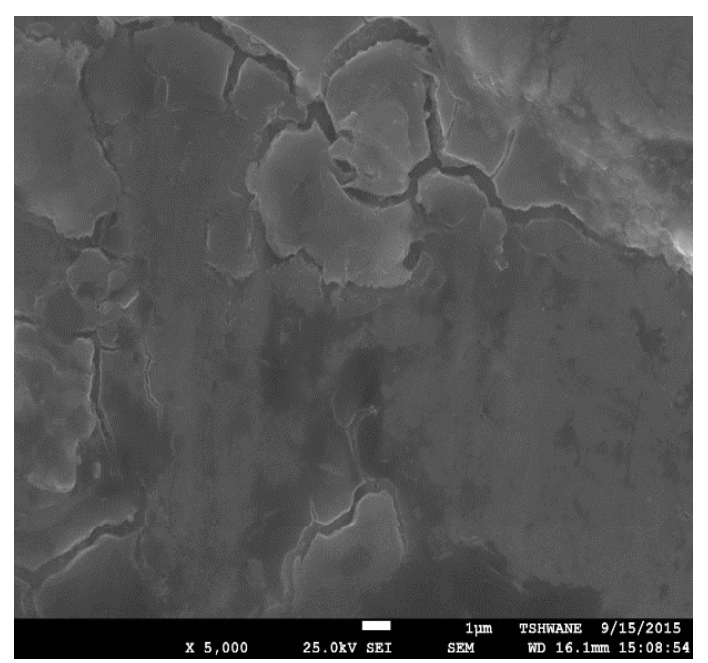

(c)

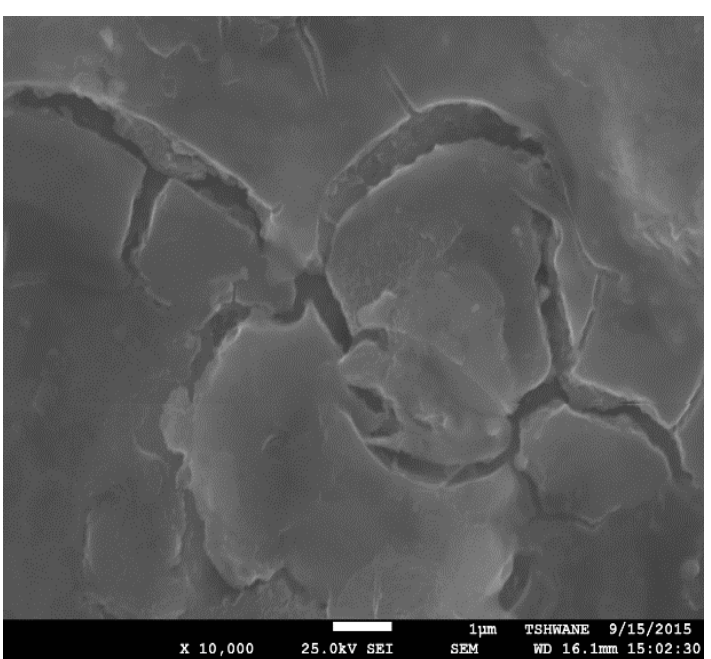

(d)

Fig. 5: SEM micrograph of Ife steel with load $15 \mathrm{~N}$ showing the wear track and the different magnification
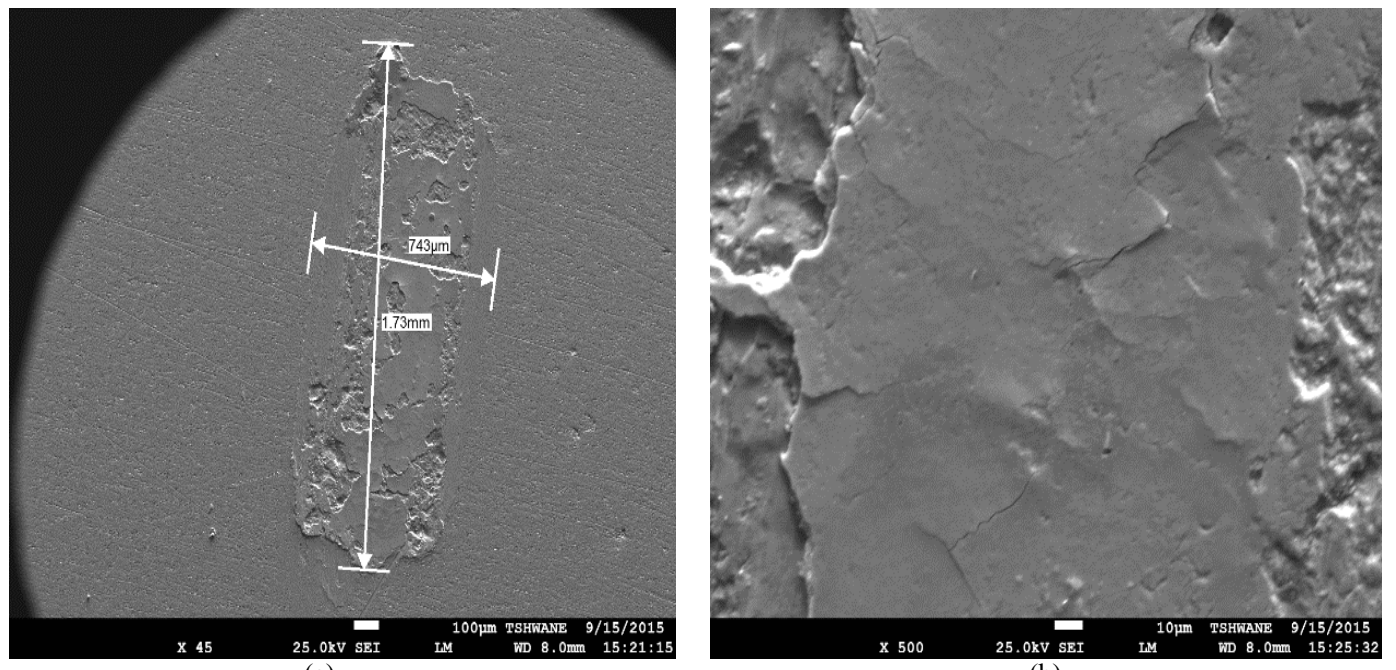

(a)

(b)

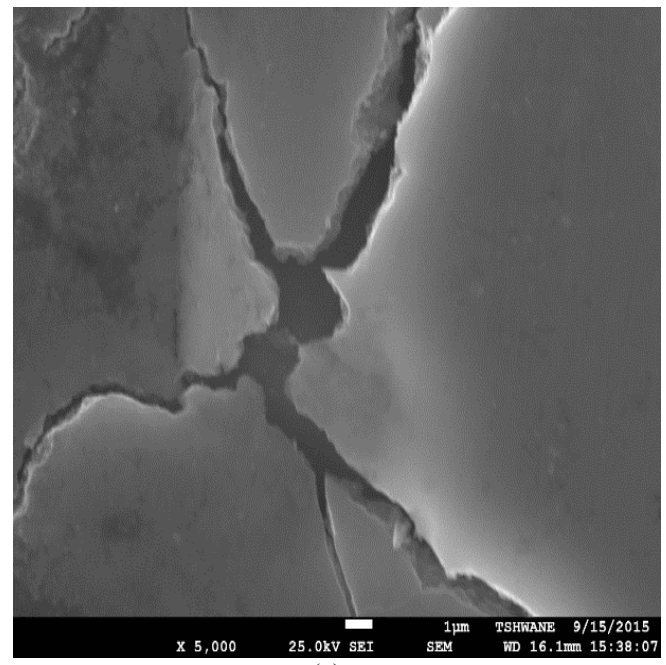

(c)

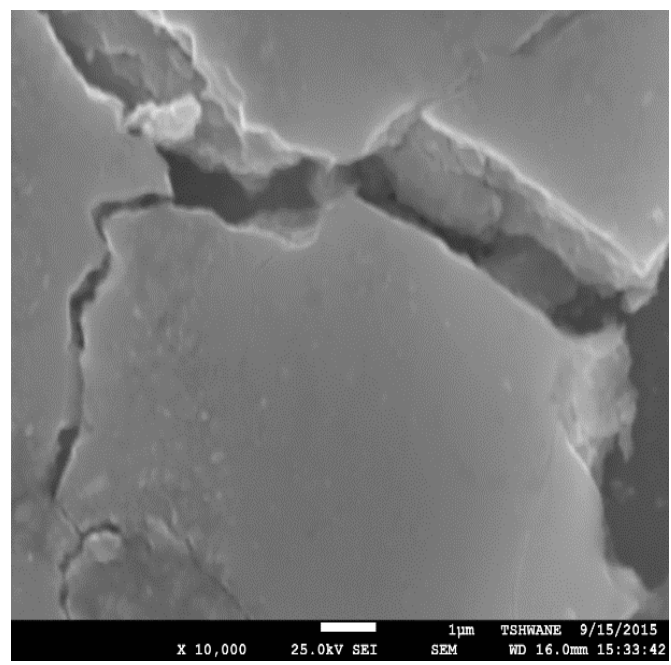

(d)

Fig. 6: SEM surface morphologies of worn surfaces of Ife Steel are shown with load $25 \mathrm{~N}$ the wear track and the different magnification 


\section{5}

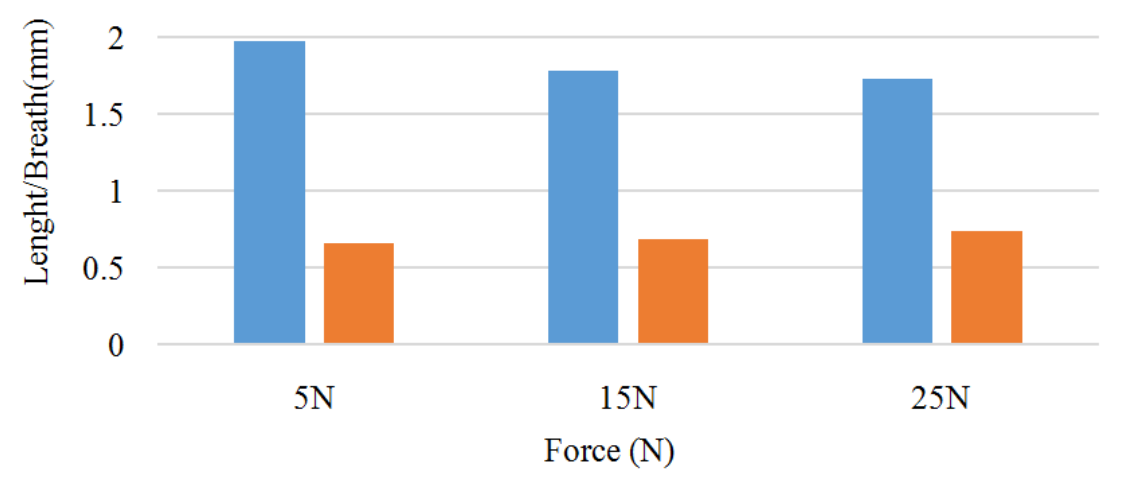

- Length $(\mathrm{mm}) \quad$ Breadth $(\mu \mathrm{m})$

Fig. 7: Bar chart for comparison of wear track dimension of Ife Iron steel

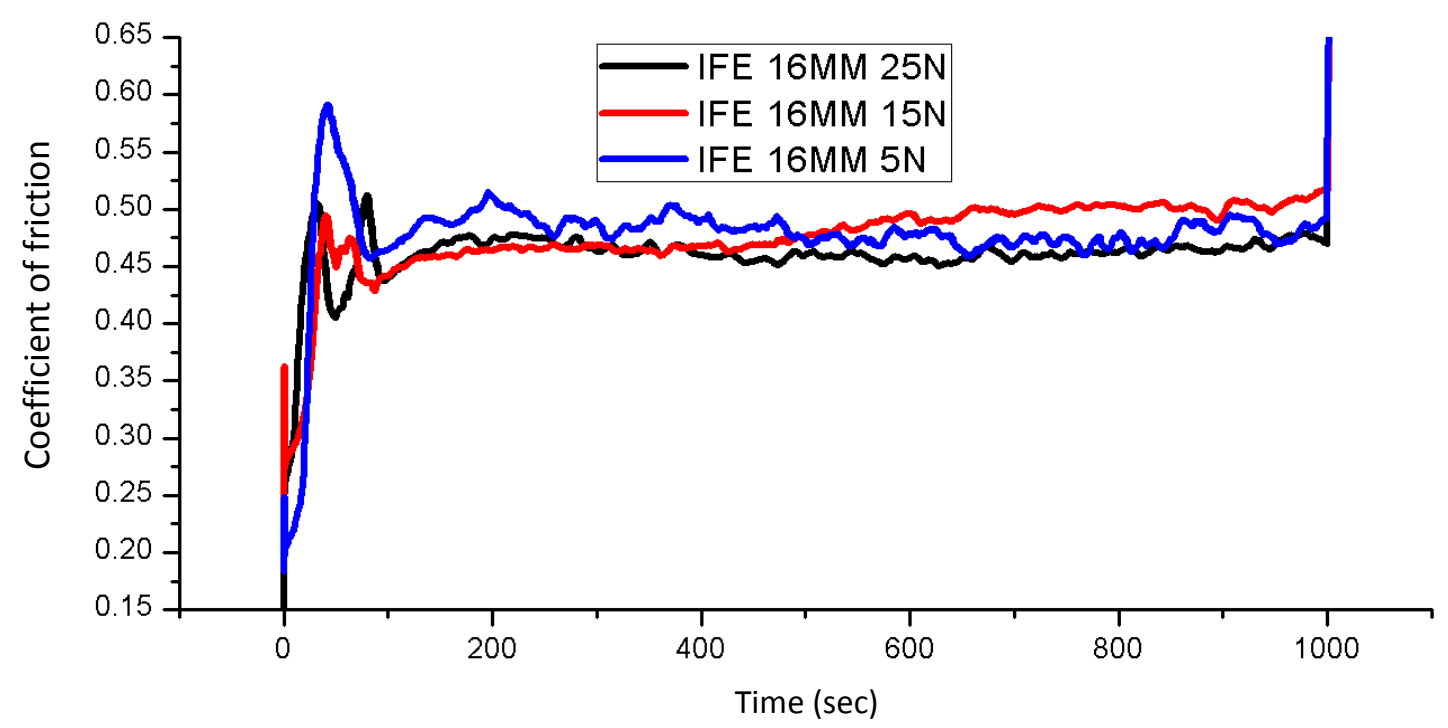

Fig. 8: Corrosion Wear Coefficient of Ife Iron

Table 2: Wear track dimension of Ife Iron steel with load 5, 15 and $25 \mathrm{~N}$

\begin{tabular}{lll}
\multicolumn{2}{c}{ and $25 \mathrm{~N}$} & \\
\hline & Length $(\mathrm{mm})$ & Breadth $(\mu \mathrm{m})$ \\
\hline $5 \mathrm{~N}$ & 1.97 & 660 \\
$15 \mathrm{~N}$ & 1.78 & 680 \\
$25 \mathrm{~N}$ & 1.73 & 743 \\
\hline
\end{tabular}

In Fig. 6 with load $25 \mathrm{~N}$, we noticed a severe crack in (c) and (d) at higher magnification of the oxide film and the inter face matrix. This assertion was in perfect agreement with the work of Mishra (2014) who opined that delamination from inside oxide film or oxide/matrix interface was considered to be normal pattern in oxidation wear. This suggests that wear behaviour mainly depends on oxide film. Table 2 showed the wear track dimension of the steel with varying loads. As the load increases, the wear track length decreases resulting in the widening of the ploughing breadth while Fig. 5 showed the bar chart comparison wear dimension. Figure 7 showed the bar chart for comparison of wear track dimension of Ife Iron steel. It can be seen that as the load increases, the wear track length dimension decreases while the breath dimension increases.

Abouei et al. (2006) in his work on the effect of microstructure on the oxidative wear behaviour of plain carbon steel opined that when a test sample is under dry sliding wear at relatively low loads, the frictional heating helps atmospheric oxidation over the sliding surface, the oxide layer gets removed by repeated and multiple contacts and wear debris of oxide particles is then generated. The wear debris gets trapped between the sliding and is compacted into a layer. The continuing process of removal of the 
transfer layer and its reformation and thickening, results in fluctuations of the friction coefficient showed Ife Iron steel COF of $16 \mathrm{~mm}$ with $5 \mathrm{~N}$ load oscillate to 0.60 and slides down to 0.47 at $80 \mathrm{sec}$ and now oscillate uniformly to $1000 \mathrm{sec}$, however $16 \mathrm{~mm}$ at $25 \mathrm{~N}$, the waveform increases to 0.50 and slides down to 0.40 before oscillating to $1000 \mathrm{sec}$ from this waveform in Fig. 8, it is clearly seen that the time to reach steady friction varies for different loads., the time for higher load to reach steady friction is less. This is because the surface roughness and other parameters attain a steady level at a shorter period of time with increase in load. This result is in agreement with the results of Chowdhury and Helali (2008).

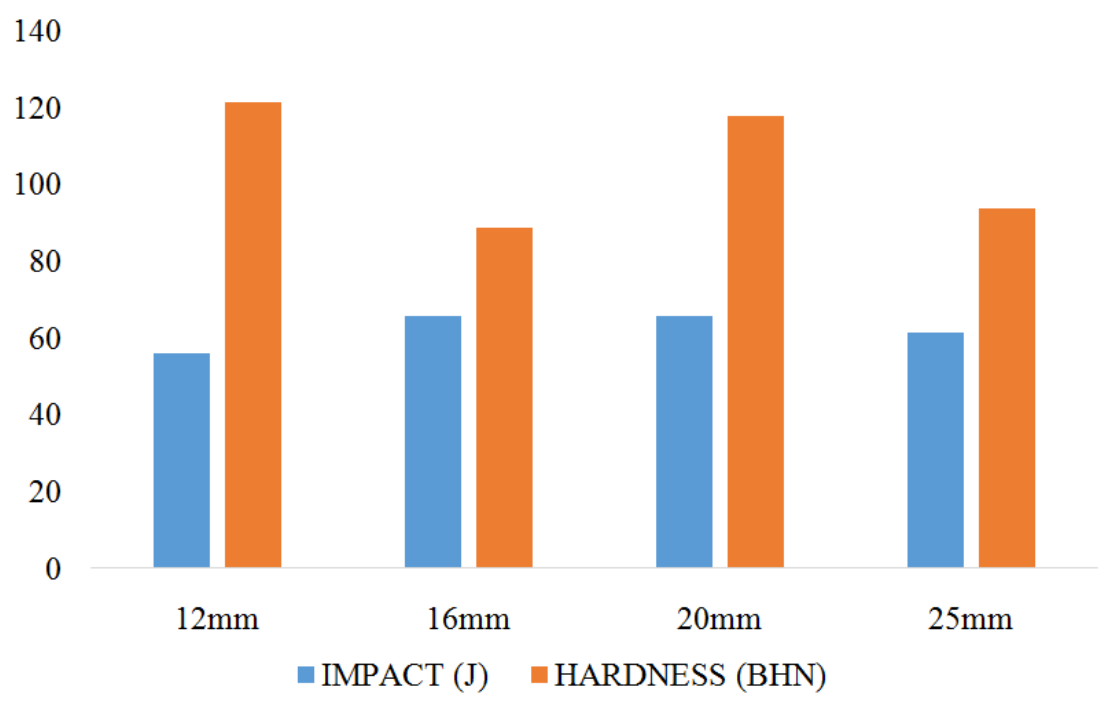

Fig. 9: Bar chart of impact and hardness test of Ife Steel

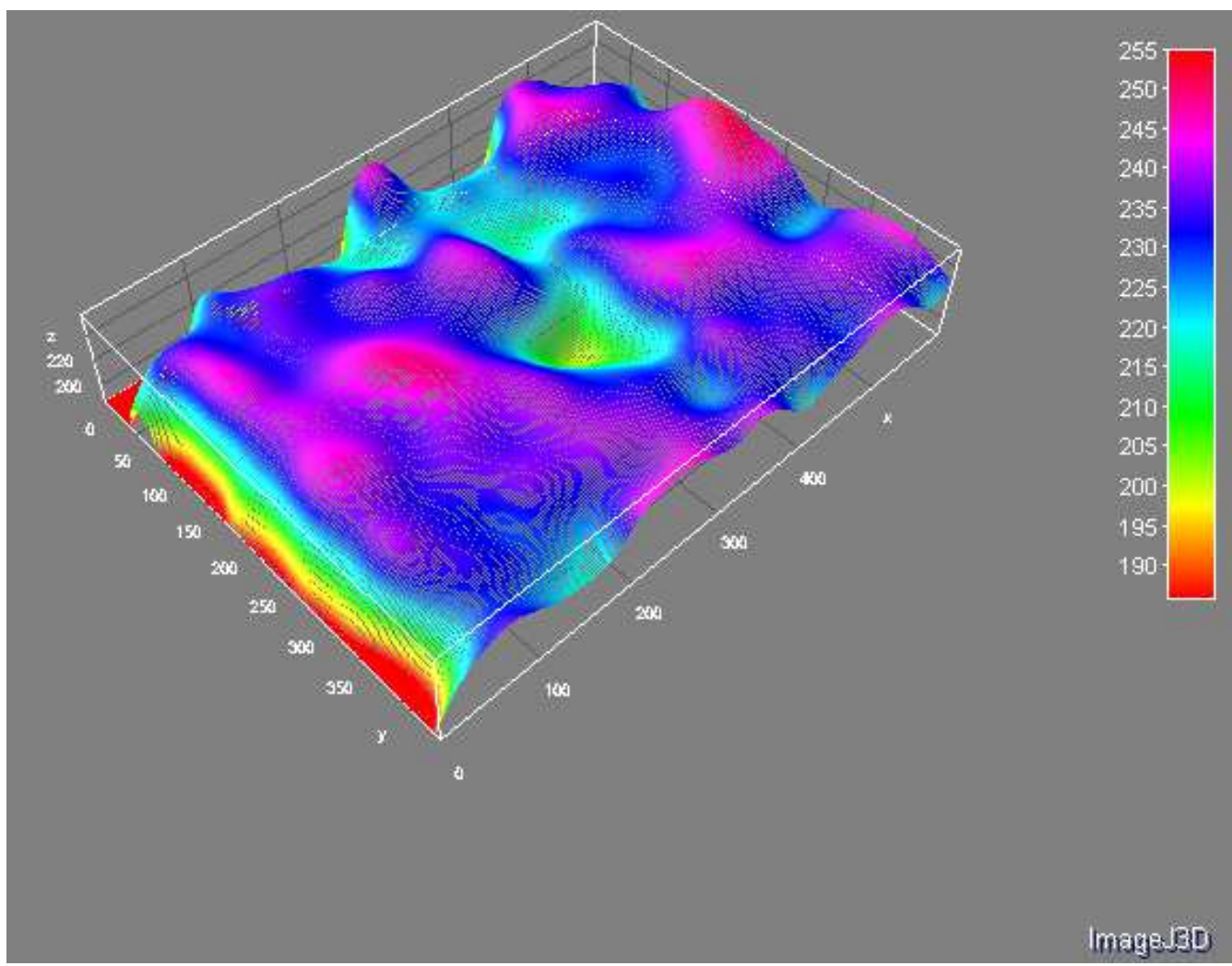

Fig. 10: Interactive 3D surface plot of the steel used 
Figure 9 showed the bar chart of Impact and Hardness value of Ife steel. It can be seen that $12 \mathrm{~mm}$ rod has the highest hardness value followed by $20 \mathrm{~mm}$ steel whereas $12 \mathrm{~mm}$ steel rod has the least value of Impart value while the $20 \mathrm{~mm}$ steel rod has the highest Impact value.

Figure 10 showed the 3D interactive surface plot drawn by intensity of any colour. It offers a basic vision of observed surface morphology of the steel such as the grid size, the smoothing and the perspective of the minimum and maximum percentage in relation to the $z$-scale. This was attested to by the work of Dang et al. (2014).

\section{Conclusion}

Effect of varying loads on wear behaviour of Ife iron constructional steel was examined. At higher load of 25 $\mathrm{N}$, there was a wide crack propagation which tends to affect the morphology of the steel. At higher load of 15 $\mathrm{N}$, the wear was governed by delamination, oxidation and plastic deformation. Therefore to have a minimum wear resistance, it is advisable to use a load of $5 \mathrm{~N}$.

\section{Acknowledgement}

The authors wish to acknowledge Prof Peter Olubambi and the management of Tshwane University of Technology, Chemical Metallurgical and Material Engineering Department, Pretoria. South Africa for the usage of their equipment for this research work

\section{Author's Contributions}

Alo Francis Ireti: The main author and the writer.

Emordi Ngozi: Contributed to the writings.

Kunle Michael Oluwasegun: Contributed to the writings and reading through the manuscripts.

Dayo Adeyemi Isadare: Preparation of the samples.

Adedayo Adewale Oyedele: Sourcing of the materials.

\section{Ethics}

We are ready to address any ethical issues that may arise after the publication of this manuscript

\section{References}

Assakkaf, I., 2002. Introduction to structural steel design, slide 2.

Abouei, V., H. Saghafian and S. Kheirandish, 2006. Effect of microstructure on the oxidative wear behavior of plain carbon steel. Wear, 262: 1225-1231. DOI: 10.1016/j.wear.2006.11.009

Ajayi, J.A., O.O. Joseph, D.T. Oloruntoba and O.O. Joseph 2013. Experimental failure investigation of an aircraft nose landing gear. Int. J. Metall. Mat. Eng., 3: 85-92.
Burwell, J.T., 1957/58. Survey of possible wear mechanisms. Wear, 1: 119-141. DOI: 10.1016/0043-1648(57)90005-4

Chowdhury, M.A. and M.M. Helali, 2008. The effect of Amplitude of vibration on the coefficient of friction for different materials. Tribol. Int., 41: 307-314. DOI: 10.1016/j.triboint.2007.08.005

Dang, A.T., T.T. Vo and V.P. Le, 2014. Analyzing 2D structure images of piezoelectric ceramics using imageJ. Int. J. Mater. Chem., 4: 88-91. DOI: $10.5923 /$ j.ijmc. 20140404.02

Elhadia, A., A. Bouchouchab, W. Jomaac, Y. Zedanc and T. Schmitte et al., 2016. Study of surface wear and damage induced by dry sliding of tempered AISI 4140 steel against hardened AISI 1055 steel. Tribol. Indus., 38: 475-485.

Gates, D., 1998. Two-body and three-body abrasion: A critical discussion. Wear, 214: 139-146. DOI: $10.1016 / \mathrm{S} 0043-1648(97) 00188-9$

Gupta, V.K. and O.P. Pandey, 2000. Wear charaeristics of plain carbon steel. Indian J. Eng. Mater. Sci., 7: 354-360

Joseph, O.O. and F.I. Alo, 2014. An assessment of the microstructure and mechanical properties of $0.26 \%$ low carbon steel under different cooling media: Analysis by one-way ANOVA. Indus. Eng. Lett., 4: 39-46.

Joseph, O.O., O.A. Abidakun, A.O. Aniyikaye and O.O. Folorunsho, 2013. Investigations on the material efficacy of failed helical gears in a gear train. Indus. Eng. Lett., 3: 46-54.

Kato, K., 2001. Modern tribology handbook.Vol One Wear Mechanisms, Tohoku University.

Kaul, R., P. Ganesh, R.V. Nandedkar and A.K. Nath, 2005. Characterization of dry sliding wear resistance of laser surface hardened En 8 steel. J. Mater. Process. Technol., 167: 83-90. DOI: 10.1016/j.jmatprotec.2004.09.085

Kumar, S. and V.K. Pathak, 2016. Effect of static load on wear behavoir of $0.58 \%$ carbon steel. Int. J. Adv. Mater. Sci. Eng., 5: 21-27. DOI: $10.14810 /$ ijamse.2016.5103

Maich, A.A., 2016. A dissertation submitted in partial satisfaction of the requirements. $\mathrm{PhD}$ Thesis.

Mishra, A., 2014. Oxidation wear mechanism of cast steels. Int. J. Mech. Eng. Rob. Res., 3: 588-592.

Mohan, S., V. Prakash and J.P. Pathak, 2002. Wear characteristics of HSLA steel. Wear, 252: 16-25. DOI: 10.1016/S0043-1648(01)00834-1

Tyagi, R., S.K. Nath and S. Ray, 2004. Development of wear resistant medium carbon dual phase steels and their mechanical properties. Mat. Sc. Tech, 20: 645-652. DOI: 10.1179/026708304225012062 